\title{
SOBRE A RELAÇÃO ENTRE O ESPIRITUALISMO DE BERGSON E A FENOMENOLOGIA DE HUSSERL NAS ORIGENS DA FILOSOFIA CONTEMPORÂNEA
}

\author{
Carlos Diogenes C. Tourinho \\ Universidade Federal Fluminense
}

Resumo: O presente artigo aborda aspectos que possibilitam relacionar o espiritualismo de Bergson e a fenomenologia de Husserl nas origens da Filosofia Contemporânea. 0 artigo aborda temas que são afins aos dois autores, tais como: a crítica ao projeto de naturalização da consciência, a temporalidade vivida como duração, a metafísica redefinida em novas bases, a intuição como método filosófico, etc. 0 artigo tem uma dupla finalidade: identificar pontos de aproximação entre os dois autores e indicar certas especificidades dos projetos filosóficos apresentados por Bergson e por Husserl no século XX.

Palavras-chave: Henri Bergson; Edmund Husserl; Consciência; Duração; Metafísica.

\begin{abstract}
This article discusses aspects that make it possible to relate the spiritualism of Bergson and the phenomenology of Husserl in the origins of the contemporary philosophy. The article discusses issues that are related to the two authors, such as the critical to project of naturalization of the consciousness, the temporality experienced as duration, the metaphysics redefined on a new basis, the intuition as philosophical method, etc. The article has a dual purpose: identify points of approximation between the two authors and indicate certain specificities of the philosophical projects presented by Bergson and Husserl in the twentieth century.
\end{abstract}

Keywords: Henri Bergson; Edmund Husserl; Consciousness; Duration; Metaphysics.

Quando pensamos em autores como Bergson e Husserl, estamos diante de dois pensadores de ascendência judia - que se convertem (que, ao menos, manifestam uma crescente aproximação), em fases distintas da vida, ao cristianismo católico e protestante, respectivamente - cujas obras podemos situar no período da história da filosofia que se convencionou chamar de 'Origens da Filosofia Contemporânea' (período que se estende, grosso modo, do último quarto do século XIX às décadas iniciais do século XX). Apesar de viverem a mesma época e de seus projetos filosóficos terem pontos que os aproxima (ambos os autores pensam a consciência em termos de uma temporalidade vivida como duração; procuram salvaguardar a metafísica, redimensionando-a em novas bases; se unem, por questões metodológicas, em 
torno do conceito filosófico de 'intuição', etc), tais autores não foram interlocutores em vida. Roman Ingarden - filósofo polonês de quem Husserl fora orientador no período de 1916 e 1917 - parece ser um dos principais responsáveis por fazer com que Husserl tomasse contato com a teoria bergsoniana da duração. A este propósito é revelador o testemunho de Ingarden, em sua participação no Troisième Colloque Philosophique de Royaumont, em 1957:

Husserl não conhecia os trabalhos de Bergson...Então Husserl leu pela primeira vez Bergson e verificou que a duração pura coincidia aproximadamente com a consciência constituinte do tempo. Em fins de 1916, Husserl leu parte de meu trabalho sobre Bergson e me disse, referindo-se à descrição da duração pura: 'É inteiramente como se eu fosse Bergson'...Quando eu mesmo expus certas teses de Bergson, Husserl me perguntou: 'De onde você tomou esta teoria?' Eu então lhe respondi: 'De Bergson'. Alguns anos mais tarde, após uma leitura visivelmente incipiente dos textos de Bergson em tradução alemã, Husserl convinha que, na maior parte das coisas, as teses de Bergson concordavam com os pontos principais de sua doutrina (INGARDEN, R. [1957] 1968, p.233/237).

Ainda a propósito do contato de Husserl com a teoria bergsoniana da duração, é importante ressaltar as considerações do sacerdote jesuíta Júlio Fragata (1920-1985) que, em sua tese de doutoramento, defendida em 1954 na Universidade Gregoriana de Roma, mas somente publicada em Braga dois anos depois, sob o título de A Fenomenologia de Husserl como fundamento da filosofia, faz a seguinte apreciação: 'A aproximação entre Husserl e Bergson é patente não só quanto ao caráter intuitivo da consciência, mas também relativamente à concepção temporal da mesma' (FRAGATA, SJ, J. 1956, p. 120). No entanto, Fragata lembra-nos que só posteriormente Husserl teve conhecimento do filósofo francês, por ocasião de uma conferência proferida por Alexandre Koyré em Göttingen, no ano de 1911. Segundo Jean Héring (um dos principais colaboradores de Husserl no período de 1906/1907), por ocasião desta mesma conferência, Husserl teria exclamado aquela altura que: 'Les bergsoniens conséquants, c'est nous' (apud FRAGATA, SJ, J. 1956, p. 120).

A despeito destes raros testemunhos dando conta de um possível contato de Husserl com a obra de Bergson, um exame minucioso permite-nos notar aspectos que atestam uma aproximação entre os projetos filosóficos da fenomenologia husserliana e do espiritualismo bergsoniano. Comecemos por observar que ambos os autores contestam, com veemência, cada um a seu modo, o projeto que ganha contornos mais nítidos no último quarto do século XIX e que nós poderíamos conceber, em termos gerais, como um projeto de 'naturalização da vida do espírito' (ou da vida interior da consciência). Desde já, podemos enumerar os seguintes dados envolvendo o referido projeto: 1) tal como as demais ciências positivistas da época, tal projeto apoia-se na doutrina 
do naturalismo, segundo a qual pensar o mundo consiste em pensá-lo unicamente como uma realidade de fatos naturais. Enquanto um ente psicofísico, o homem seria um fato natural em meio a outros, confinado a uma relação meramente empírica com os demais entes mundanos; 2) tal projeto alia-se às ciências naturais nos moldes do positivismo do século XIX (concepção para a qual conhecer não é senão observar sistematicamente o fenômeno, descrevendo-o em sua regularidade, com o objetivo de inferir indutivamente generalizações empíricas); 3) acrescenta-se que o referido projeto somente se consolida a partir de uma transposição da doutrina naturalista, do modelo positivista de ciência e, sobretudo, do método experimental das ciências da natureza para o campo da Psicologia; 4) como resultado desta transposição, apoiado no paralelismo psicofísico de Theodor Fechnner (1801-1887) surge, em Leipzig, o projeto pioneiro de uma psicologia dita 'científica' ou 'experimental' de Wilhem Wundt (1832-1920); 5) do entusiasmo com este projeto, é possível notar o crescimento de uma tendência que se expande no último quarto do século XIX, para a qual o próprio Husserl nos chamaria à atenção, sobretudo, a partir de 1900, qual seja: a tendência 'psicologista' de fundamentar a Matemática, a Lógica e, até mesmo, a própria Filosofia em processos psicológicos, de modo que tais áreas não fossem concebidos senão como disciplinas específicas da psicologia (dentre os autores que irão compartilhar esta tendência, segundo Husserl, destacam-se: Wilhem Wundt, Stuart Mill, Theodor Lipps, dentre outros)1.

Uma apreciação inicial permite-nos notar, claramente, a contestação de Bergson e de Husserl ao que denominamos de projeto de 'naturalização da vida do espírito'. Ambos os autores apostam em uma filosofia que não perde de vista uma distinção de domínios, ou uma 'dualidade', que coloca, de um lado, um domínio do que é propriamente 'espiritual' e, de outro, um domínio do que habita o espaço (do que é próprio de uma realidade de fatos naturais). Já a partir de sua tese de doutoramento para a língua francesa, intitulada Essai sur les données immédiates de la conscience (1889), para contestar a referida naturalização da consciência, Bergson apresenta-nos uma filosofia que, em especial, no Capítulo 2 da referida obra, remete-nos para a seguinte 'distinção' e suas respectivas correlações: a distinção entre os corpos justapostos nos espaço e os momentos que se sucedem continuamente na consciência. Correlativamente, o autor remete-nos para a distinção entre uma 'multiplicidade quantitativa' (própria da justaposição dos corpos no espaço) e

1 Para uma abordagem mais precisa dos autores ditos 'psicologistas', citados por Husserl em Prolegômenos à Lógica Pura (Cf. Tourinho, C. D. C. 'A 'concessão dolorosa' de Husserl na segunda edição de Prolegômenos: a ideia de verdade em si', p.569). 
uma 'multiplicidade por penetração mútua' (própria dos momentos que se desenrolam, em uma duração continua, no interior da vida consciente). Tais multiplicidades tornam-se, por sua vez, segundo Bergson, correlatas à distinção entre o que significa diferir o mesmo do outro em sentido 'numérico' e em sentido 'qualitativo'. Se os corpos justapostos no espaço se distinguem apenas numericamente (isto é, se distinguem pelo lugar que ocupam no espaço), os momentos da vida consciente distinguem-se uns dos outros, a partir de suas respectivas relações com o passado e com o futuro (distinguem-se, portanto, apenas em sentido qualitativo, uma vez que, diferentemente dos corpos no espaço, tais momentos da vida consciente não se encontram separados uns dos outros por intervalos vazios, mas prolongam-se em um fio contínuo de duração) ${ }^{2}$. Neste sentido, o ponto principal da crítica de Bergson ao projeto de naturalização da vida do espírito (ou da consciência) consiste na inclinação naturalista em tomar a multiplicidade que é própria de uma temporalidade vivida como duração em termos de uma analogia com o número, inserindo, com isso, o espaço no domínio do tempo, tomando-o em termos de uma grandeza numérica e, deste modo, em termos do que esse domínio propriamente 'não é'.

Com uma preocupação parecida, contra a tendência psicologista que, no último quarto do século XIX, procura fundamentar a matemática, a lógica e a própria filosofia em processos psicológicos (portanto, contra autores como Theodor Lipps, para quem a lógica não é senão uma 'física do pensar'; como Stuart Mill, para quem o princípio de não contradição consiste apenas na incompatibilidade da ocorrência simultânea de dois estados de consciência contrários, e assim por diante), Husserl apresenta-nos, a propósito do debate sobre a fundamentação da lógica e da sua relação com a psicologia, em Prolegomena zur reinen Logik (1900), volume propedêutico às Investigações Lógicas (Logische Untersuchungen), a sua crítica ao psicologismo com vistas a garantir a distinção entre os domínios do real e do ideal. Husserl nos diz que, ao tomar o pensamento como um 'fato natural', procurando fundamentar a lógica na psicologia, as tendências psicologistas confundiriam o ato de pensar com o conteúdo ideal deste ato, incorrendo, assim, em problemas de fundamentos. Husserl lembra-nos, na referida obra, que são inteiramente distintos o juízo como ato psicológico de pensar e o juízo como unidade ideal da lógica. Lembremo-nos do famoso exemplo da 'máquina de calcular', apresentado por Husserl ao final do \22 de Prolegômenos, no qual nos chama à atenção para a

2 Sobre a distinção entre as multiplicidades 'quantitativa' e 'qualitativa', bem como entre o que significa distinguir o mesmo do outro em sentido 'numérico' e em sentido 'qualitativo' (Cf. Bergson, H. Essai sur les données immédiates de la conscience, p.81). 
heterogeneidade entre as 'leis gerais da aritmética' e as 'leis mecânicas' que explicam o funcionamento da máquina. Ninguém apelaria, ao tentar explicar tal funcionamento, para as leis da aritmética em detrimento das leis mecânicas determinantes do funcionamento da máquina. Para Husserl, o erro maior dos psicologistas consistiria, então, em ignorar as diferenças fundamentais entre 'lei ideal' e 'lei real'. Em outros termos, as leis causais segundo as quais o pensamento se desenvolve de modo a poder justificar-se pelas normas ideais da lógica e estas mesmas normas seriam, portanto, segundo Husserl, coisas inteiramente distintas.

Se Bergson e Husserl apoiam-se, inicialmente, contra o projeto de 'naturalização da vida do espírito' (Husserl fala-nos, em 'Philosophie als strenge Wissenschaft', artigo publicado em 1911, para o primeiro número da Revista Logos, de uma 'naturalização da consciência' ou 'naturalização das ideias'), numa certa dualidade que, por sua vez, nos remete para uma distinção de domínios (em Bergson, para uma distinção entre o corpo e o espírito, entre o espaço e o tempo; em Husserl, para uma distinção entre o real e o ideal), tais autores não deixam, contudo, num segundo momento, de pensar o importante problema da relação entre tais domínios. Bergson começa a se ocupar mais detidamente desse problema em Matière et Mémoire (1896), ao passo que Husserl arrisca algumas considerações iniciais sobre o problema em questão já em Prolegomena zur reinen Logik (1900).

No caso de Bergson, um indício desta nova preocupação pode ser notado, de um lugar privilegiado, no prefácio à sétima edição da referida obra de 1896, no qual o autor problematiza a suposta relação de dependência entre os domínios da consciência e do cérebro, procurando pensá-la em termos de uma relação de 'solidariedade'. Daí Bergson utilizar, no referido prefácio, a famosa metáfora da relação entre o prego e a roupa, afirmando-nos:

Que haja solidariedade entre o estado de consciência e o cérebro, é incontestável. Mas há solidariedade também entre a roupa e o prego onde ela está pendurada, pois, se retirarmos o prego, a roupa cai. Diremos por isso que a forma do prego indica a forma da roupa...? (BERGSON, H. [1896] 1959, p. 164).

A substituição de tal relação de dependência por uma relação de solidariedade entre a consciência e o cérebro é o que permitiria a Bergson formular, já a partir de Matière et Mémoire, a hipótese da coextensão da consciência à vida. Afinal, conforme destaca Bergson, alguns anos mais tarde, na conferência ' $\mathrm{La}$ Conscience et la Vie', pronunciada em inglês, na Universidade de Birmingham, em 29 de maio de 1911, em homenagem ao biólogo Thomas Huxley: 'Costuma-se dizer às vezes: 'Em nós, a consciência está ligada a um cérebro; por isto, é preciso atribuir a consciência aos seres vivos que possuem um cérebro e recusá-la aos outros” (BERGSON, H. [1911] 
1959, p.819). O autor nos diz, nesta mesma conferência, que é possível perceber, imediatamente, o vício desta argumentação, pois: 'Raciocinando da mesma maneira, poderíamos dizer também: 'A digestão está ligada em nós a um estômago; por isto os seres vivos que possuem estômago digerem, os outros não digerem" (BERGSON, H. [1911] 1959, p.819). Ao formular tal hipótese, Bergson abre as portas para que o seu espiritualismo desça, para além do homem, ao nível da matéria viva.

Já Husserl esboça uma abordagem do problema da relação entre o real e o ideal em Prolegômenos (1900). Ao insistir, por uma questão de fundamentos, em distinguir os domínios do real e do ideal, Husserl manifesta uma preocupação que o acompanharia por muitos anos: alerta-nos que a verdade não pode derivar dos fatos, pois deles somente extraímos 'generalizações vagas da experiência' (vage Verallgemeinerungen der Erfahrung). Husserl deixa-nos claro que, ao identificar as leis do conteúdo do ato com as leis que regulam o processo psicológico, os psicologistas acabam por fazer com que a verdade que constitui o conteúdo do ato dependa diretamente do processo psíquico, isto é, da constituição da natureza humana, o que inevitavelmente levar-nos-ia a afirmar que tal verdade não existiria se não existisse essa constituição. Conforme Husserl esclarecerá, no \36 da referida obra: 'O que é verdadeiro é absolutamente verdadeiro, é 'em si' verdadeiro' (HUSSERL, E. [1900/ 1913a], 1968, p.117)³. Husserl nos lembrará, no mesmo parágrafo, que a constituição da espécie humana é um fato e a partir de fatos somente podemos derivar 'fatos'. Por conseguinte, toda tentativa de fundar a verdade sobre tal constituição implicaria em conferir à verdade um 'caráter de fato', o que seria, para Husserl, um contrassenso, uma vez que todo fato é individual e, portanto, temporalmente determinado (e segundo o autor, não faria sentido algum atribuir à verdade o discurso de uma determinação temporal). Por um lado, Husserl afirma-nos que a verdade não poderia depender da constituição da natureza humana, pois, a aceitação de tal dependência abalaria o próprio sentido da ideia de verdade. Daí Husserl dizer, no $\int 39$, que: 'Determinar a verdade por meio da referência à comunidade da natureza significa renunciar ao seu conceito’ (HUSSERL, E. [1900/ 1913a], 1968, p.131). Por outro lado, e é aí que nos deparamos com o importante problema da relação entre os domínios do real e do ideal, Husserl não deixa de ressaltar que, apesar de não podermos atribuir à verdade qualquer determinação temporal, ela não se encontra 'algures no vazio', uma vez que há

3 Sobre a ideia de 'verdade em si' em Prolegômenos, bem como sobre as implicações da conservação dessa ideia na segunda edição de Investigações Lógicas, em 1913 (Cf. Tourinho, C. D. C. 'A 'concessão dolorosa' de Husserl na segunda edição de Prolegômenos: a ideia de verdade em si', p.563-580). 161 
uma 'apreensão intelectiva' ou uma 'vivência consciente' da verdade. Enquanto conteúdo ideal do pensamento, a verdade não deriva do ato psicológico de pensar e, no entanto, tal conteúdo é visado por intermédio do pensar e, além disso, é visado nele. Sobre tal conteúdo ideal do pensamento, o autor afirmanos, no \39: 'Ele pode ser visado no pensar, mas não pode ser produzido no pensar' (HUSSERL, E. [1900/1913a], 1968, p. 132). Isto é, apesar da distinção entre o ato de pensar e o seu conteúdo ideal, há uma espécie de 'vivência de apreensão' deste conteúdo.

Contra a tendência da psicologia experimental do séc. XIX de tornar homogêneos domínios que são inteiramente distintos, ao apostarem numa certa dualidade para salvaguardar a especificidade da 'vida do espírito', Bergson e Husserl reservam um lugar especial ao conceito filosófico de 'consciência'. Afinal, como nos diz Bergson, em 'La Conscience et la Vie'(1911): 'Quem diz espírito diz, antes de tudo, consciência' (BERGSON, H. [1911] 1959, p.818). O autor pensa, primeiramente, a consciência como 'memória' (isto é, como conservação e acumulação do passado nos momentos que se sucedem ininterruptamente no fluxo da duração). Como ele próprio nos diz, ainda na conferência de 1911: 'consciência significa primeiramente memória...a memória existe ou não existe consciência...toda consciência é, pois, memória conservação e acumulação do passado no presente' (BERGSON, H. [1911] 1959, p.818). Por outro lado, Husserl pensa a consciência como 'intencionalidade', retendo, como herança do pensamento de Brentano, a ideia básica segundo a qual toda consciência é consciência de alguma coisa. $\mathrm{O}$ autor nos diz, nas 'Cinco Lições' (Fünf Vorlesungen) - proferidas em abril-maio de 1907, em Göttingen - que: 'As vivências de conhecimento possuem, isto pertence à sua essência, uma intentio, visam algo, se reportam de tal ou tal maneira a uma objetividade' (HUSSERL, E. [1907] 1950, p. 55). Já no \ 84 de Ideen I (1913), Husserl descreve a intencionalidade como 'a peculiaridade em virtude da qual as vivências são vivências de alguma coisa' (HUSSERL, E. [1913] 1976, p.171). E ainda, em Cartesianische Meditationen (1931), o autor afirma, no $\ 14$, que: 'A palavra intencionalidade não significa outra coisa senão esta particularidade fundamental e geral da consciência de ser consciente de algo, de portar, em sua qualidade de cogito, seu cogitatum nela mesma' (HUSSERL, E. [1931] 1973, p. 72).

A despeito de conceberem, primeiramente, a consciência como 'memória' e como 'intencionalidade', respectivamente, Bergson e Husserl pensam a vida interior da consciência em termos de uma temporalidade vivida como duração. Tal concepção já se faz notar, em Bergson, desde Essai sur les données immédiates de la conscience (1889). Trata-se de uma espécie de 'senha' para o acompanhamento do itinerário bergsoniano a partir da referida obra (e talvez 
seja difícil identificar outro conceito que tenha tanta importância para Bergson). Já Husserl, somente a partir dos cursos de 1904/1905, juntamente com outros aditamentos sobre o tema até 1910 - compilados em 1917 por Edith Stein, mas somente publicado em 1928, sob a edição de Heidegger, nos traz considerações sobre a ideia de uma temporalidade vivida como duração na imanência da própria consciência fenomenológica.

E é justamente por pensar, primeiramente, a consciência como 'memória' e, portanto, por pensá-la em termos daquilo a que toda duração supõe (uma vez que, sem memória, não há duração), é que podemos notar, de imediato, em Bergson, a indissociabilidade entre pensar a consciência e a ideia de uma temporalidade vivida como 'duração', isto é, vivida como um antes que se conserva continuamente no depois, pela força de uma memória que a acompanha. Em Husserl, diferentemente, deparamo-nos com uma abordagem 'estática' e 'genética' da fenomenologia. Se a primeira tem como fio condutor a análise da unidade de sentido do objeto intencionado na consciência, a segunda concentrar-se-á sobre as conexões entre os vividos intencionais, bem como sobre a compossibilidade de tais vividos, em seus horizontes de inatualidades passadas e futuras, cujo passado imediato e o futuro iminente são, respectivamente, retencionado e protencionado na vivência de um presente atual. Mesmo reconhecendo, já nos cursos da primeira década do século XX, a importância e a complexidade das questões relacionadas à gênese temporal da consciência, Husserl privilegia, claramente, uma abordagem estática do problema da constituição dos objetos em 1913, em Ideen $I^{4}$. Não é claro, contudo, no itinerário husserliano, o que faz com que Liçoes para a fenomenologia da consciência interna do tempo (Vorlesungen zur Pbänomenologie des inneren Zeitbewnsstseins), que inclui cursos de 1905 e acréscimos até 1910, só venha a público em 1928, e a totalidade de suas investigações sobre o tempo (19171918), nas Lições e Manuscritos de Bernau (cuja edição ficara, posteriormente, a cargo de Eugen Fink) também tenha se mantido desconhecida do grande público. Em Ideen I (1913), destaca-se, em toda a obra, apenas o $\ 81$ intitulado 'O tempo fenomenológico e a consciência do tempo' ('Der

\footnotetext{
${ }^{4}$ Pedro Alves (2003) chama-nos à atenção para a limitação do texto de Ideias I, afirmando-nos que: '...a elisão, nele operada, da problemática do tempo é, eo ipso, a sua limitação a um modelo estático, não genético da constituição objetal...Isso assentava, em última instância, no facto de a constituição aí tematizada ser ainda uma constituição estática. $O$ objeto intencional era simplesmente tomado tal como se oferecia, ele funcionava como um simples índice ou fio condutor. $E$ a análise constitutiva cifrava-se, justamente, na explicitação dos diversos extratos de sentido, uns sobre os outros depositados, e na sua referenciação às formas correspondentes de consciência originariamente doadora'. Cf. Alves, P. Subjetividade e Tempo na Fenomenologia de Husserl, p.389-390. 
phänomenologische Zeit und das Zeitbewußtsein') - a tratar da teoria husserliana de uma temporalidade fenomenológica.

Husserl identifica um 'tempo objetivo' - denominado de 'cósmico' (kosmischen Zeit) - com o qual lidamos em nosso modo natural de consideração do mundo (modo esse compartilhado pelas ciências naturais) e um 'tempo fenomenológico' (phänomenologische Zeit), vivido como duração, na própria imanência da consciência fenomenológica. Com a abordagem genética da fenomenologia, Husserl desloca-nos à atenção para uma temporalidade que é própria da vivência de intencionar algo. Tal temporalidade é apresentada em termos de uma vivência de 'duração', como um fluxo contínuo e ininterrupto de vividos intencionais que, conforme se tornam atualizados, passam a ser vividos como um 'agora efetivo' (wirkliches Jetzt $t$. Na medida em que passam, se tornam o que foi vivido como agora 'ainda há pouco' ('Soeben) e, com isso, se juntam aos demais vividos intencionais inatuais ('ex-agoras'), retidos intencionalmente em um novo agora respectivo, e assim sucessivamente. Trata-se do que Husserl chamou de 'retenção' (Retention). Daí ele próprio dizer: o agora que não é mais, vivido ainda há pouco, ainda 'ressoa' em um agora efetivo. Husserl é levado a comparar, no $\ 11$ de Lições para a fenomenologia da consciência interna do tempo (1928), o ressoar da retenção com a 'cauda de um cometa' (Kometenschweif) (HUSSERL, E. [1928] 1969, p. 30). Já a 'protensão' seria a expectativa de um agora que está por vir, que já começa a 'ecoar' (essa expectativa por um futuro iminente é, segundo Husserl, uma retenção em sentido inverso). O tempo fenomenológico torna-se, assim, um conjunto de 'agoras' e, por conseguinte, um conjunto de vividos intencionais que se desenrolam continuamente na imanência da própria consciência fenomenológica. Daí Husserl dizer, no $\ 81$ de Ideen I, que essa temporalidade é uma 'forma necessária de vinculação entre vividos' (HUSSERL, E. [1913] 1976, p. 182). Tais vividos intencionais atados uns aos outros em fluxo duram, nos termos de Husserl, nas 'Cinco Lições' (1907), em 'um eterno rio heraclitiano de fenômenos' (ein ewiger Heraklitischer Flu $\beta$ von Phänomenen) (HUSSERL, E. [1907] 1950, p. 47). A intencionalidade retentiva e protentiva não só mantém o objeto vivido no agora efetivo, mas efetua o elo entre aquele agora e o novo.

Uma breve apreciação das teorias bergsoniana e husserliana da temporalidade como vivência de duração permite-nos notar os seguintes pontos em comum: 1) esta temporalidade imanente à consciência não deve se confundir com a ideia do tempo como 'grandeza numérica', pensado linearmente. Como o próprio Husserl nos diria, posteriormente, em 'Philosophie als strenge Wissenschaft' (1911), a vivência desta temporalidade como duração não é senão a vivência: '...do 'tempo' imanente, sem princípio e fim, um tempo que nenhum cronômetro mede’ (HUSSERL, E. 1911, p.313); 
ou ainda, dois anos mais tarde, no $\int 81$ de Ideen I (1913): '...de um tempo que não é medido em geral pela posição do sol, pelo relógio, nem por meio físico algum’ (HUSSERL, E. [1913] 1976, p. 181). Acresecenta-se, além disso, que esta sucessão de agoras não deve ser pensada linearmente. O tempo fenomenológico não é a passagem por uma série de agoras, colocados lado a lado, como em uma 'linha'. Neste sentido, ambos os autores parecem preservar a especificidade da sucessão que é própria dessa temporalidade. Cabe-nos notar que Bergson se preocupa, desde Essai (1889), em distinguir a ideia de uma sucessão que é própria dos corpos que habitam o espaço (uma sucessão na qual o antes se encontra em uma exterioridade recíproca com o depois, ou seja, trata-se de um antes $e$ um depois) e a sucessão que é própria dos momentos que se desenrolam continuamente uns nos outros (uma sucessão na qual o antes se dá no depois); 2) tanto em Bergson quanto em Husserl, vemos a ideia da consciência como um elo de ligação entre o passado e o futuro. Bergson fala-nos, em 'La Conscience et la Vie' (1911), da consciência como um 'traço de união entre o passado e o futuro, como uma ponte entre o que foi e o que será' (BERGSON, H. [1911] 1959, p. 819). Empregando termos muito próximos, Husserl afirma que a consciência é essencialmente consciência de algo e é esta intencionalidade retentiva e protentiva um ‘elo de ligação’ entre os ex-agoras e aqueles que estão por vir; 3) considerado como um instante matemático, a ideia do 'presente' é uma mera abstração para ambos os autores. A esse respeito, Bergson nos diz, na mesma conferência de 1911:

\footnotetext{
Reter o que já não é, antecipar o que ainda não é, eis a primeira função da consciência. Não haveria para ela o presente se este se reduzisse ao instante matemático. Esse instante é apenas o limite, puramente teórico, que separa o passado do futuro; ele pode a rigor ser concebido, não é jamais percebido; quando cremos surpreendê-lo, ele já está longe de nós (BERGSON, H. [1911] 1959, p.819).
}

Em uma linha de pensamento muito próxima, Husserl fala-nos que se considerarmos como um 'instante' este 'agora efetivo' vivido no fluxo da duração, desatando-o dos demais vividos intencionais, este agora se tornará inapreensível. A despeito dos pontos que aproximam os dois autores, a teoria husserliana de uma temporalidade vivida como duração parece se encontrar 'mais à vontade' com a ideia do presente. Em seu artigo de 1903, Bergson nos diz que: '(...) nosso passado nos segue, cresce sem cessar a cada presente que incorpora em seu caminho’ (BERGSON, H. [1903] 1959, p. 1397). Já em Husserl, o campo fenomenal - que é o da própria consciência fenomenológica - revela, em sua imanência, a referência intencional aos objetos e uma vez que esta referência intencional é vivida como um agora efetivo, em um fluxo 
contínuo de agoras, revela-se o 'ser temporal' (zeitliche Sein) da intentio. A própria consciência se abre como um 'campo de presença' que abriga a compossibilidade dos horizontes de inatualidades passadas e futuras, concetadas com os agoras vividos sucessivamente em um presente atual. Podese dizer que haveria, pelo menos, dois sentidos de 'presente' em Husserl: 1) como campo de presença, a consciência seria como que um 'grande agora', assegurando a referida compossibilidade; 2) um 'agora efetivo' (wirklichen Jetzt) que se desenrola continuamente, sucedendo os agoras anteriores e dando lugar para os agoras que estão por vir. O segundo sentido do agora encontrar-se-ía no coração do primeiro.

Voltemo-nos para outro aspecto que, a despeito das especificidades dos dois projetos filosóficos, aproxima os autores em questão. Um olhar panorâmico na história da filosofia contemporânea revela-nos que o século XX foi marcado, tanto na filosofia continental, quanto na filosofia analítica, pela afirmação do fim da metafísica ${ }^{5}$. Ao mesmo tempo em que vertentes da filosofia no século XX anunciam-nos, por caminhos distintos, o fim da metafísica, nas origens da filosofia contemporânea, Bergson e Husserl esforçam-se em preservar a metafísica, redefinindo-a em novas bases. Bergson fala-nos, em 'Introduction à la Métaphysique', artigo publicado para a Revue de Métaphysique et de Morale em 1903, na metafísica como '(...) a ciência que pretende dispensar os símbolos’ (BERGSON, H. [1903] 1959, p.1396). Já Husserl fala-nos, nas Cinco Lições (1907), de uma espécie de 'vocação metafísica' da teoria do conhecimento que, enquanto fenomenologia do conhecimento, no exercício de sua tarefa positiva, ao conservar no pensamento a pergunta pela essência do fenômeno cognoscitivo, reivindica uma apreensão intuitiva do ser, em sentido absoluto e último, do próprio fenômeno cognoscitivo. Husserl não exitará em equiparar a teoria do conhecimento a uma 'fenomenologia do conhecimento', concebida, a partir de então, como '(...) o fragmento primeiro e básico da fenomenologia em geral' ('...das erste und Grundstück der Phänomenologie überhaupt') (HUSSERL, E. [1907] 1950, p.23).

${ }^{5}$ Como é bastante conhecido na literatura sobre filosofia contemporânea, Heidegger denuncia-nos, na década de 20, que a tradição metafísica hegemônica no Ocidente fora a principal responsável pelo esquecimento da pergunta pelo sentido do Ser (daí a necessidade em Heidegger de uma 'franca recuperação' desta questão, o que justificaria para este autor a retomada de uma ontologia fundamental entendida como uma 'analítica existencial do Dasein'). Por outro lado, dentro deste mesmo cenário contemporâneo, na filosofia analítica da linguagem, deparamo-nos com autores, tais como Mach, Wittgenstein, Carnap, dentre outros, cujas teses compartilham, grosso modo, a concepção segundo a qual os ditos problemas metafísicos não seriam senão 'pseudoproblemas'. A análise conceitual da linguagem denunciaria que tais problemas resultariam de um mau uso da linguagem, sendo os mesmos destituídos de sentido, uma vez que incorreriam inevitavelmente em equívocos categoriais. 
No artigo de 1903, Bergson se refere à metafísica como um 'verdadeiro empirismo'. Daí ele próprio nos dizer que: 'Mas, um empirismo verdadeiro é aquele que se propõe apegar-se o mais possível ao original mesmo, aprofundar-lhe a vida e, por uma espécie de auscultação espiritual, sentir palpitar sua alma; e este empirismo verdadeiro é a verdadeira metafísica' (BERGSON, H. [1903] 1959, p.1408). Já Husserl cita-nos, no $\ 20$ de Ideen I, a fenomenologia - em sua vocação para conhecer as coisas em sua doação originária - como um 'autêntico positivismo' ('ecbten Positivismus'). Daí ele próprio nos dizer que: 'Se por 'positivismo' entende-se o esforço, absolutamente livre de pressupostos, para fundar todas as ciências sobre o que é 'positivo', isto quer dizer sucetível de ser apreendido de maneira originária, então, somos nós os autênticos positivistas!' (HUSSERL, E. [1913] 1976, p.45). Em ambos os autores, em seus respectivos projetos ditos 'metafísicos', vê-se o anseio pela apreensão de um absoluto. Tal anseio impõe-nos, tanto em um projeto quanto em outro, a exigência de estabelecer um método que lhe é próprio. E é aí que notamos a aproximação de tais autores em torno do conceito filosófico de 'intuição'. Em Bergson, trata-se de um 'simpatizar-se com a coisa', de um esforço a partir do qual adentramos na duração do objeto, atingindo, assim, o absoluto. Nos termos do autor: '(...) decorre daí que um absoluto só poderia ser dado numa intuição, enquanto todo o restante é objeto de análise' (BERGSON, H. [1903] 1959, p.1395); o autor chama de 'intuição': '(...) a simpatia pela qual nos transportamos para o interior de um objeto para coincidir com o que ele tem de único e, consequentemente, de inexprimível' (BERGSON, H. [1903] 1959, p.1395). Já Husserl - logo nos primeiros parágrafos da Primeira Investigação de Investigações Lógicas - parte da distinção entre a chamada 'intenção significativa' (Bedeutungsintention) e 'intenção intuitiva', ou 'intuição de preenchimento' (erfüllender Anschauung), mostrando-nos que, no caso da percepção, os atos intencionais significativos vão sendo, pouco a pouco, preenchidos intuitivamente pela presença do objeto visado, realizando, gradativamente, a referência objetiva até que seja alcançada uma 'perfeição da adequação' (Vollkkommenheit der Adäquation) entre o pensamento significativo do intelecto e a coisa visada significativamente e plenamente intuída.

Sobre a relação entre o simbólico e o intuitivo, em Bergson, deparamo-nos com formas de conhecimento que se opõem, ao passo que, em Husserl, são atos intencionais distintos - meramente significativo e intuitivo que se unificam em uma síntese. No primeiro caso, Bergson opõe as duas formas do conhecimento: análise e intuição (a primeira 'se detém no relativo', ao passo que a segunda 'atinge o absoluto'; opõe-se uma reação tipicamente simbólica a uma apreensão intuitiva e, portanto, absoluta da coisa; isso não impedirá, contudo, que Bergson pense a relação entre as duas formas de 167 
conhecimento: não se pode passar dos conceitos à intuição, mas, podemos passar da intuição aos conceitos). No segundo caso, com Husserl, os atos intencionais são, antes de tudo, 'atos meramente significativos'. Na medida em que apenas visam os seus objetos, tais atos significativos são 'vazios' de preenchimento intuitivo; eventualmente, tais atos tornam-se 'intuitivos' e, com isso, ganham, gradativamente, um preenchimento, através da presença da coisa visada. Mas, esta presença do que é visado se faz em diferentes graus ou níveis de evidenciação, gerando um aumento progressivo do conhecimento do objeto, em termos de vivacidade ou riqueza do que é intencionado, confirmando, com isso, em gradações ou níveis crescentes, a realização (ou atualização consciente) da referência objetiva. Tem-se, então, em Husserl, uma distinção fundamental e uma eventual síntese entre intenção de significação 'intuitivamente vazia' e 'intuitivamente preenchida'. Tais gradações de preenchimento intuitivo inclinam-se, em cada ato, para um 'limite ideal' de preenchimento, um 'ideal de preenchimento definitivo' (Ideal der letżten Erfüllung) que, por sua vez, equivaleria à presença absoluta do objeto ${ }^{6}$.

Acrescenta-se ainda que, em ambos os autores, é possível notar a ideia de uma 'radicalidade' que é própria da filosofia: em Bergson, poderíamos localizar tal radicalidade na especificidade do seu espiritualismo, sobretudo, a partir da formulação da hipótese da coextensão da consciência à vida, fazendo a 'vida do espírito' descer, ao longo da escala dos seres vivos, ao nível da matéria viva. Em Husserl, tal radicalidade encontra-se na própria intenção primária de constituir a filosofia como uma 'ciência de rigor', na especificidade da reflexividade fenomenológica e do próprio campo fenomenal para o qual a redução fenomenológica nos desloca a atenção, campo em cuja imanência tudo aquilo que aparece se mostra como dado 'efetivo e autêntico' (wirkliche und eigentliche Gegebenheit) à consciência, revelando-se, em sua totalidade, como fenômeno. Trata-se, portanto, nos termos de Husserl, de uma 'terra firme de dados' (Festlande von Gegebenheiten'), domínio do 'dar-se em si mesmo' das coisas em sua doação originária. Portanto, a radicalidade de não se contentar com nenhum grau de evidenciação das coisas que fique aquém de uma

\footnotetext{
${ }^{6}$ Para um exame mais minucioso da distinção e síntese entre intenções meramente significativas (e, portanto, intenções 'intuitivamente vazias') e intenções 'intuitivamente preenchidas', bem como para um exame da concepção husserliana de um 'ideal de preenchimento intuitivo', remetemos, primeiramente, 0 leitor para os §§ 1-9 do Capítulo 1 da Primeira Investigação e, num segundo momento, para o § 16 do Capítulo 3 da VI Investigação. Cf. Husserl, E. Logische Untersuchungen. Zweiter Band. Teil I. 'Untersuchungen zur Phänomenologie und Theorie der Erkenntnis', p.23-39; Cf. Husserl, E. Logische Untersuchungen. Zweiter Band. Teil II. 'Elemente einer phänomenologischen Aufklärung der Erkenntnis', p.64-67.
} 
evidenciação apodítica, o que equivale, nos termos do autor, a uma 'ausência absoluta de dúvida' (absolute Zeifellosigkeit) (HUSSERL, E. [1931] 1973, p.55).

Husserl morre em 1938 e Bergson em 1941. O primeiro jamais renunciou, no curso do seu extenso itinerário acadêmico, a um esforço incansável em torno do projeto de constituição da filosofia como uma 'ciência rigorosa', intenção primária que acompanharia Husserl de suas Investigacõos Lógicas (1900) à Crise das Ciências Européias (1936). Ao almejar a realização de tal projeto, Husserl se dedica, desde muito cedo, com um ímpeto espantoso, aos problemas de fundamentação da matemática, da lógica e da própria filosofia (nunca é demais lembrar que o mesmo autor escreveu, em vida, cerca de 40.000 páginas em estilo estenográfico). Enquanto uma espécie de 'herdeira da modernidade' em pleno século XX, a fenomenologia husserliana é saudada por Charles Andler - nas célebres conferências realizadas por Husserl na Sorbonne, em 1928 - como 'a primeira grande filosofia clássica depois de Hegel' (KELKEL, A. L. \& SCHÉRER, R., 1964, p.14). Já o segundo autor dedica-se, por sua vez, a um projeto filosófico original, cuja duração e unidade peculiar revelam, pouco a pouco, ao menos, de Ensaio (1889) à Evolução Criadora (1907), as marcas inconfundíveis da vida do espírito ('duração', 'discernimento' e 'élan vital'). Bergson entrelaça, com isso, uma nova concepção da metafísica com um espiritualismo que desce, para além do homem, aos organismos mais elementares - aos quais podemos ainda atribuir algum tempo que dura e, portanto, uma memória que conserva e contrai os momentos vividos pelo organismo - na escala evolutiva dos seres vivos. $O$ ineditismo de tal projeto filosófico, bem como a repercussão do mesmo no cenário intelectual europeu da primeira metade do século XX, faz com que Bergson receba, em 11 de março de 1967, a justa homenagem com uma placa no Phantéon de Paris, contendo a seguinte inscrição: 'Philosophe dont l'oeuvre et la vie ont honoré la France et la pensée bumaine " (LEDUC, E. 2013, p.38). Trata-se, portanto, quando consideramos os nomes de Edmund Husserl e Henri Bergson, de autores cujas obras representam, na primeira metade do séc. XX, verdadeiros capítulos na história da filosofia, exercendo, deste modo, influxos que não deixam de influenciar, decisivamente, os rumos da Filosofia Contemporânea.

\section{Referências Bibliográficas}

ALVES. P. M. S. Subjetividade e Tempo na Fenomenologia de Husserl. Lisboa: Centro de Filosofia da Universidade de Lisboa, 2003. 
BERGSON, H. "Essai sur les données immédiates de la conscience". In: Oeuvres. Édition du Centenaire. Paris: Presses Universitaires de France, ([1889] 1959).

. "Matière et Mémoire. Essai sur la relation du corps a l'esprit". In: Oenvres. Édition du Centenaire. Paris: Presses Universitaires de France, ([1896] 1959).

_. “Introduction à la Métaphysique'. La Pensée et le Mouvant”. In: Oewvres. Édition du Centenaire. Paris: Presses Universitaires de France, ([1903] 1959).

. “'La Conscience et la Vie' L'Énergie Spirituelle”. In: Oeuvres. Édition du Centenaire. Paris: Presses Universitaires de France, ([1911] 1959).

. "L'Évolution Créatrice". In: Oewvres. Édition du Centenaire. Paris: Presses Universitaires de France, ([1907] 1959).

FRAGATA SJ, J. A Fenomenologia de Husserl como fundamento da filosofia. Braga: Livraria Cruz, 1956.

HUSSERL, E. Logische Untersuchungen. Erster Band. Prolegomena zur reinen Logik. Halle a. d. S.: Max Niemeyer, ([1900/ 1913a], 1968).

. Logische Untersuchungen. Zweiter Band. Teil I. 'Untersuchungen zur Phänomenologie und Theorie der Erkenntnis'. Stuttgart, Tübingen: Max Niemeyer Verlag, ([1901] 1913b, 1968).

. Logische Untersuchungen. Zweiter Band. Teil II. 'Elemente einer phänomenologischen Aufklärung der Erkenntnis'. Stuttgart, Tübingen: Max Niemeyer Verlag, ([1901] 1913c, 1968).

. Die Idee der Phänomenologie - Fünf Vorlesungen. Husserliana. (Band II). Netherlands: Martinus Nijhoff, ([1907] 1950).

. "Philosophie als strenge Wissenschaft". In: Logos: Zeitschrift für systematische. Philosophie/Logos, 1910-1911, 53 Seite (n), p.289-341.

Ideen zu einer reinen Phänomenologie und phänomenologischen Philosophie. Erstes Buch: Allgemeine Einführung in die reine Phänomenologie. The Hague, Netherlands: Martinus Nijhoff, ([1913] 1976).

. "Vorlesungen zur Phänomenologie des inneren Zeitbewusstseins". In: Husserl, E. Zur Phänomenologie des inneren Zeitbewusstseins (1893-1917). Husserliana (Band X). The Hague, Netherlands: Martinus Nijhoff ([1928] 1969).

Cartesianische Meditationen und Pariser Vorträge. Husserliana (Band I). Den Haag, Netherlands: Martinuos Nijhoff, ([1931/ 1929] 1973). 
INGARDEN, R. "El problema de la constituición y el sentido de la reflexión constitutiva en Husserl / Discusión: H. G. Gadamer, R. Ingarden, J. Wahl, A. Schütz, R. P. Van Breda". In: Husserl - Cahiers de Royaumont. Tradução de Amalia Podetti. Buenos Aires: Paidos, p.215-238, 1968 [1957].

KELKEL, A. L. \& SCHÉRER, R. Husserl: sa vie, son oewvre avec un exposé de sa philosophie. Col. Philosophes. Paris: Presses Universitaires de France, 1964.

LEDUC, E. Dictionnaire du Phantéon (de Paris). Paris: Publibook, 2013.

TOURINHO, C. D. C. 'A 'concessão dolorosa' de Husserl na segunda edição de Prolegômenos: a ideia de verdade em si'. In: Revista de Filosofia Aurora, v.29, n.39, 2014, p.563-580. 